\title{
Potential for Preventing Diabetes and Dementia by Consuming Unpolished Rice Blended with Black Unpolished Rice and Super-Hard Rice
}

\author{
Sumiko Nakamura ${ }^{1}$, Takashi Hara ${ }^{2}$, Akira Yamazaki ${ }^{3}$, Atsushi Kobayashi ${ }^{3}$, Satoshi Maeda ${ }^{3}$, \\ Kensaku Kasuga ${ }^{4}$, Jotaro Aii ${ }^{1}$, Ayana Nakano ${ }^{1}$, Hiroshi Goto ${ }^{5}$, Masao Hirayama ${ }^{5}$, Kenichi \\ Watanabe $^{5}$, Toshiko Koide ${ }^{5}$, Osamu Yamaguchi ${ }^{6}$, Takashi Nagamine ${ }^{7}$, Mitsutoshi Ito ${ }^{1}$, \\ Hiroshi Tanaka ${ }^{1}$, Takeshi Ikeuchi ${ }^{4}$ and Ken'ichi Ohtsubo ${ }^{1 *}$
}

${ }^{1}$ Faculty of Applied Life Sciences, Niigata University of Pharmacy and Applied Life Sciences, 265-1, Higashijima, Akiha-ku, Niigata, 9568603, Japan

${ }^{2}$ Faculty of Agriculture, Niigata University, Niigata, Japan

${ }^{3}$ Echigo Seika Co., Ltd. Japan

${ }^{4}$ Department of Molecular Genetics, Brain Research Institute, Niigata University, Niigata, Japan

${ }^{5}$ Niigata Bio-Research Park Co., Ltd. Japan

${ }^{6}$ Fukuoka Agriculture and Forestry Research Center, Japan

${ }^{7}$ Hokuriku Research Station, Central Region Agricultural Research Center, NARO, Japan

*Corresponding author: Ken'ichi OHTSUBO, Niigata University of Pharmacy and Applied Life Sciences, 265-1, Higashijima, Akihaku, Niigata City, Niigata, 956-0841 Japan

\section{ARTICLE INFO}

Received: 慧 August 03, 2019

Published: 蔧 August 19, 2019

Citation: Sumiko Nakamura, Takashi Hara, Akira Yamazaki, Atsushi Kobayashi, Ken'ichi Ohtsubo, et al. Potential for Preventing Diabetes and Dementia by Consuming Unpolished Rice Blended with Black Unpolished Rice and Super-Hard Rice. Biomed J Sci \& Tech Res 20(4)-2019. BJSTR. MS.ID.003483.

Keywords: Alzheimer's Disease; Diabetes; $\beta$-secretase; Black Rice; $\beta$-Glucan-Rich Waxy Barley; Resistant Starch

\section{ABSTRACT}

Type-2 diabetes, which may prompt Alzheimer's disease, can be regulated by diet. We investigated the palatability and efficacy of consuming two diets rich in $\beta$-glucan or resistant starch by blending ordinary polished rice and polished waxy barley (5:5) or by blending ordinary unpolished rice, unpolished pigmented rice and polished super-hard rice $(2: 4: 4)$, then subjecting the blends to high-pressure treatment before cooking. After subjects consumed these diets for 12 weeks, consumers of the former rice blend had significantly less body fat, lower blood glucose levels. The latter blend showed higher antioxidant capacity and inhibition against $\beta$-secretase than control, and the subjects, consuming the latter blend, showed not only lower blood glucose levels, but also a higher ratio of amyloid $\beta 42 / 40$ peptide than the subjects consuming the traditional rice diet. Long-term consumption of the latter blended rice diets might inhibit rises in postprandial blood glucose levels and impede amyloid $\beta$ production.

Abbreviations: Ae Mutant: Amylose Extender Rice Mutant, $A \beta$ : Amyloid $\beta$ Peptide Protein, BACE1: $\beta$-Secretase, HPT: High-Pressure Treatment, KBH Rice: "Koshihikari" Unpolished Rice Blended with Black Unpolished Rice And Super-Hard Rice (Ratio 2:4:4), KWB Rice: "Koshihikari" Polished Rice Blended with Polished Waxy Barley (Ratio 5:5), BGL: Blood Glucose Level, AUC: Area Under Rising Limb of a Glucose Curve for Postprandial Blood Glucose, AUCi: Area Under The Rising Limb of an Insulin Curve, FBG: Fasting Blood Glucose Level, RS: Resistant Starch, BFP: Body Fat Percentage, LDL: LowDensity Lipoprotein, HDL: High-Density Lipoprotein

\section{Introduction}

According to WHO report, globally, an estimated 422 million adults were living with diabetes in 2014 , and diabetes of all types can lead to complications in many parts of the body and increase the overall risk of dying prematurely [1]. Therefore, there is an urgent need to implement population-based interventions that prevent diabetes, enhance its early detection, and use lifestyle and 
pharmacological interventions to prevent or delay its progression to complications [2]. The WHO and Food and Agriculture Organization of the United Nations recommend foods with low glycemic index (GI) to prevent diabetes [3]. The concept of GI was introduced by Jenkins et al. [4] as a ranking system for carbohydrates based on their immediate impact on blood glucose levels, and low GI and glycemic load diets have more recently been widely recommended for the prevention of chronic diseases including diabetes, obesity, cancer and heart disease, [5] because the resulting glycemic index classification of foods provided a numeric physiologic classification of relevant carbohydrate foods in the prevention and treatment of diseases such as diabetes [6]. The glycemic effect of food depends on numerous factors, including the structure of amylose and amylopectin [7]. The amylopectin found in amylose extender (ae) rice mutants (e.g., "Chikushikona85"cultivar) contains more longchain glucans than normal (non-mutant) rice, thereby making the texture of the mutant rice grains very hard and non-sticky after boiling, which renders it less palatable than traditional rice [8]. Wada et al. showed that the rise in blood sugar after consuming cookies made from "Chikushi-kona85" rice flour was significantly less than when consuming cookies made from the traditional rice cultivar [9] Several studies have reported the development of highly resistant starch (RS) rice [10,11] (via physical or chemical mutation), as well as high-amylose and high-dietary fiber rice [12].

Barley, used as food, malt, and as feedstock in Japan, is rich in $\beta$-glucan. Beta-glucan is a linear polysaccharide of glucose monomers and water-soluble dietary fiber (SDF). Several recent studies, in both hypercholesterolemic and healthy subjects, found that the daily consumption of $5 \mathrm{~g}$ of $\beta$-glucan significantly lowers total and LDL cholesterol in serum $[13,14]$. Waxy barley cultivars are a typical component of specialized foods. It imparts a sticky texture to foods and contains a total $\beta$-glucan content that is higher than normal isotypes of barley [15].

The production of short-chain fatty acids in $\beta$-glucan may also be a probable mechanism behind its observed metabolic effects. Moreover, fermentation of oat $\beta$-glucan has been shown to yield larger amounts of propionate, which has been shown to significantly inhibit cholesterol synthesis in humans [16-18].

Several studies report that long-term consumption of RS may lower fasting cholesterol and triglyceride levels $[19,20]$. Robertson et al. showed that $30 \mathrm{~g} \mathrm{RS} / \mathrm{d}$ added to the habitual diet of healthy subjects resulted in a significant decline in subcutaneous abdominal adipose tissue, non-esterified fatty acid (NEFA), and glycerol release [21].

High-pressure treatment (HPT), a technological process that limits the negative effects of food preparation on hydro-soluble vitamins, is recognized as being very useful in preserving nutritional quality in foods [22,23]. Yamakura et al. [24] showed that subjecting rice to HPT before cooking results in more free amino acids and stickier cooked rice.
In previous studies, we developed a novel method for inhibiting abrupt postprandial blood glucose levels (BGL) in Sprague-Dawley rats by feeding them ae-mutant rice (super-hard rice) soaked with functional food ingredients that had been subjected to HPT before preparation [25]. Furthermore, when we pre-prepared (with HPT) "Koshihikari" rice blended with black rice (HPT KO) at a ratio of 6:4 (using a randomized, single-blind, crossover-designed study) , we found that BGL in subject at 90 and 120 min after ingesting the cooked HPT KO was significantly lower than BGL following ingestion of the cooked "Koshihikari" (polished) rice alone. In fact, the increase in amyloid $\beta 40$ peptide in blood 120 min after eating HPT KO rice tended to be lower than amyloid $\beta 40$ after ingesting the cooked "Koshihikari" rice [26].

Recent epidemiological studies have suggested a link between Alzheimer's disease (AD), and type 2 diabetes mellitus associated with insulin resistance [27-29]. Diabetes is a lifestyle disease, and its prevention and treatment are extremely important in improving longevity and quality of life. Low glycemic index (GI) foods inhibit rapid increases in blood glucose and insulin secretion after meals. The $\beta$-amyloid precursor protein (APP) generates the amyloid $\beta$ peptide $(A \beta)$ via $\beta$ - and $\gamma$-secretase in a highly regulated process. Because working memory is impaired by $\mathrm{AD}$, the disease has spawned dynamic research investigating the influence of gammaaminobutyric acid (GABA) on working memory performance in AD sufferers [30]. It is well-recognized that the prevalence of dementia is higher in diabetic patients than in non-diabetic subjects [31], and Tokutake et al. [32] showed that there is a molecular link between $\mathrm{AD}$ and insulin signaling.

Molecules in rice with antioxidant activity include phenolic acids, flavonoids, anthocyanins, proanthocyanidins, tocopherols, tocotrienols, $\gamma$-oryzanol, and phytic acid. Rice bran also contains a variety of functional substances, such as $\gamma$-oryzanol, ferulic acid, sterol, wax, ceramide, phytin, inositol, and protein [33]. In previous studies, black rice bran contained more oleic acid and anthocyanin and showed greater BACE1 inhibitory activity than "Koshihikari" (a traditional, premium polished rice). Jensen et al. [34] and Qureshi et al. [35] showed that an increased daily consumption of bran significantly reduced the risk of coronary heart disease and lowered total cholesterol, LDL cholesterol, and triglycerides in serum. Abe et al. [36] showed that rice components that included inositol hexaphosphate significantly inhibited $A \beta$ production in neuroblastoma cells without causing cytotoxicity, suggesting that such foods might prevent AD.

Pigmented rice contains naturally occurring pigmented flavonoids known as anthocyanins. Positive health effects have been reported for the pigments in the bran layer of rice. For example, consumption of red and black rice by rabbits has been found to reduce their atherosclerotic plaque formation and increase antioxidants, ostensibly by increasing concentrations of high-density lipoprotein cholesterol and apolipoprotein A1 [37]. In previous studies, we found that a super-hard rice bread blended 
with black rice bran (SRBBB), which contained a high amount of resistant starch (RS), provided a strong inhibitory activity against $\beta$-secretase (BACE1) and acetylcholinesterase, even after heating. Furthermore, aged mice fed the SRBBB diet for 4 weeks showed lower amyloid $\beta 40$ peptide in their blood than mice fed a commercial feed diet [38].

In this study, we sought to develop a novel food product that could reduce abrupt increases in postprandial blood glucose spikes after meals for the main purpose of the experimental study, and as a side effect, those of inhibit $A \beta$ protein production after meals. We examined the effects of two blended rice blend diets and a traditional diet of standard polished rice on insulin sensitivity, concentration of LDL to HDL cholesterol ratio, and body fat percentage (BFP). Both blended diets were cooked after HPT pretreatment of rice grains. One blended diet was comprised of super-hard rice blended with black unpolished rice (HPT KBH rice) and the other comprised of a $\beta$-glucan-enriched rice blend diet (HPT KWB rice). We used a 12-wk supplementation period with $1.6 \mathrm{~g}$ RS/d, and with $2.9 \mathrm{~g} \beta$-glucan/d, compared with placebo, in 36 healthy subjects (slightly higher BGL) and assessed the results statistically.

\section{Materials and Methods}

\section{Materials}

We used four rice varieties and a mutant barley variety as food material. The ae-mutant rice cultivar "Chikushi-kona 85" was cultivated in 2017 in an experimental field at Fukuoka Agriculture and Forestry Research Center, Japan [9]. The high-dietary-fiber mutant rice cultivar "Goami2", developed in Korea, was provided to us by Dr. Hae Chune Choi in 2017. We purchased the high quality, premium, polished rice "Koshihikari" and the black rice "Okunomurasaki" from a local market. The waxy mutant barley cultivar "Haneumamochi" was cultivated in 2017 in an experimental field at the Hokuriku Research Center of the Central Agriculture Research Center, NARO, Japan.

\section{Preparation of Unpolished Rice Flour Samples and Polished Barley Grain Sample}

We prepared unpolished rice flour with a cyclone mill (SFC-S1; Udy, Fort Collins, CO, USA) screened with $1 \mathrm{~mm}$ diameter pores. Polished barley grain sample was prepared from barley seeds to be $70 \%$ yield ratio by barley pearling system 3RSB-10 (Hoden kogyo, Kyoto).

\section{Food Processing of Experimental Diets}

We blended "Koshihikari" (unpolished rice) with "Okunomurasaki" (black unpolished rice), "Chikushi-kona 85" (unpolished, super-hard rice), and "Goami 2" (polished super-hard rice) at a ratio of 2:4:2:2, which we called KBH rice. We mixed "Koshihikari” (polished rice) with "Haneumamochi" ( $\beta$-glucan-rich, polished waxy barley) at a ratio of 5:5, which we called KWB rice. Both rice mixtures were treated in a high-pressure machine (Ishikawajima-Harima Heavy Industries Co., Ltd., Tokyo, Japan) at $200 \mathrm{MPa}$ for 2 min and cooked with an Echigo Seika, Co., Ltd. The standard-diet rice "Koshihikari" (polished and aseptically cooked) was purchased from a local market. All measurements and analyses were conducted in triplicate after sample preparation or cooking.

\section{Moisture Content of Rice Flour}

We measured the moisture content of the brown rice and cooked brown rice using the ovendrying method. Brown rice samples $(2 \mathrm{~g})$ were dried for $1 \mathrm{~h}$ at $135^{\circ} \mathrm{C}$, whereas cooked rice samples $(2 \mathrm{~g})$ were dried for $3 \mathrm{~h}$ at $135^{\circ} \mathrm{C}$. Cooked rice samples were stored at $-80{ }^{\circ} \mathrm{C}$ followed by lyophilizing the sample in a freeze dryer (FD-1; Tokyo Rikakikai Co., Ltd., Tokyo, Japan). Rice flour was prepared using a cyclone mill (SFC-SI; Udy Corp., Fort Collins, USA) screened with 1 $\mathrm{mm}$ diameter pores.

\section{Measurement of Iodine Absorption Spectra}

We measured the iodine absorption spectrum of milled rice with a Shimadzu UV-1800 spectrophotometer and estimated its apparent amylose content (AAC) using the iodine colorimetric method (as described by Juliano) [39]. The iodine absorption spectrum was analyzed [40] from 200 to $900 \mathrm{~nm}$ using a square cell with an inner dimension of $1 \times 1 \mathrm{~cm}$. (The control was distilled water in the same-sized cell.) We measured absorbance at $\lambda$ max (i.e., peak wavelength) in the visible light range of iodine-stained starch because the intensity of iodine staining in starch has a high correlation with the length of glucan chains, the molecular size of amylose, and super-long chains (SLCs), as well as providing data on $\lambda \max , A \lambda \max$, the $\lambda \max / A \lambda \max$ ratio. From these values, we introduce the term "New $\lambda$ max," which we derived as New $\lambda \max =$ $(73.307 \times \mathrm{A} \lambda \max +0.111 \times \lambda \max -73.016) /(\lambda \max$ of various rice starches $-\lambda$ max of glutinous starch).

\section{Glucose Content}

To each flour sample, we added $1 \mathrm{~mL}$ of $60 \%$ ethanol to a tube with $0.1 \mathrm{~g}$ of brown rice flour and then rotated the tube at $20^{\circ} \mathrm{C}$ for $1 \mathrm{~h}$ to extract glucose. The solution was then centrifuged at 1500 $\times \mathrm{g}$ for $15 \mathrm{~min}$, and the resulting supernatant was collected as a sample solution. We determined glucose content of each sample solution using the nicotinamide adenine dinucleotide phosphate enzyme assay method, measured with a glucose assay kit (Roche, Darmstadt, Germany).

\section{Physical Properties of Boiled Rice Grains}

We measured physical properties of cooked rice grains, based on $10 \mathrm{~g}$ of rice grains per sample, using a My Boy System Tensipresser (Taketomo Electric Co., Tokyo, Japan), according to the method described by Okadome et al. [41] The bulk measurements were taken six times, from which we calculated the mean for each sample.

\section{Measurement of RS}

RS of freeze-dried rice samples was measured according to the official method established by AOAC, using an RS assay kit (Mega- 
zyme Ltd., Wicklow, Ireland). Each sample $(0.1 \mathrm{~g})$ was digested with pancreatin and amyloglucosidase at $37^{\circ} \mathrm{C}$ for $6 \mathrm{~h}$. Then, we measured glucose content using a spectrophotometer set at $510 \mathrm{~nm}$.

\section{Beta-Glucan Assay Method}

We measured $\beta$-glucan in freeze-dried rice samples according to the official method of $\mathrm{AOAC}$, using a $\beta$-glucan assay kit (Megazyme Ltd., Wicklow, Ireland). We measured $\beta$-glucan content by adding $0.2 \mathrm{~mL}$ of $50 \%$ ethanol to each rice flour sample $(0.1 \mathrm{~g})$ and then adding $5.0 \mathrm{~mL}$ of sodium phosphate buffer ( $20 \mathrm{mM}$, pH 6.5), stirring the tubes on a vortex mixer, and then incubating the tubes in a boiling water bath for approximately $2 \mathrm{~min}$. Then, we removed the tubes and vigorously stirred them on a vortex mixer, heated the tubes at $50{ }^{\circ} \mathrm{C}$ for $5 \mathrm{~min}$, and added $0.2 \mathrm{~mL}$ of lichenase (10 U) to each tube. We then capped the tubes, stirred, and incubated them at $50{ }^{\circ} \mathrm{C}$ for $1 \mathrm{~h}$. We then added aliquot of $5.0 \mathrm{~mL}$ of sodium acetate buffer (200 mM, pH 4.0) and stirred the tubes on a vortex mixer. The tube remained at room temperature for $5 \mathrm{~min}$ and then was centrifuged at $1000 \times \mathrm{g}$ for $10 \mathrm{~min}$. The supernatant was removed, and $0.1 \mathrm{~mL}$ aliquots were transferred to three test tubes; to one we added $0.1 \mathrm{~mL}$ of sodium acetate buffer (50 mM, pH 4.0) (the reaction blank) and to the other two tubes (the reaction) we added $0.1 \mathrm{~mL}$ of $\beta$-glucosidase ( $0.2 \mathrm{U}$ ) in $50 \mathrm{mM}$ acetate buffer $(\mathrm{pH} 4.0$ ). We then incubated the tubes at $50{ }^{\circ} \mathrm{C}$ for $10 \mathrm{~min}$, added GOPOD reagent $3.0 \mathrm{~mL}$ to each tube, and incubated them at $50{ }^{\circ} \mathrm{C}$ for 20 min. We measured glucose content with a spectrophotometer set at $510 \mathrm{~nm}$.

\section{BACE1 Inhibitory Activity}

We determined BACE1 inhibitory activity of freeze-dried rice samples using a BACE1 activity detection kit (Fluorescent; SigmaAldrich Co. LLC. Tokyo, Japan). To obtain the measurements, we first extracted $0.1 \mathrm{~g}$ of rice flour with $0.5 \mathrm{~mL}$ of $10 \mathrm{mM}$ acetate buffer (pH 5.0) solution ( $0.1 \%$ Triton and $0.05 \%$ CHAPS) at room temperature for $1 \mathrm{~h}$. We then centrifuged the solution at $1000 \times \mathrm{g}$ for $15 \mathrm{~min}$ and used an adsorption filter (MILLEX-GN33 mm: Merk Millipore Co Ltd. Tokyo, Japan) to remove the colored component from the extracted solution. We then added the sample to a 96-well tissue culture plate (AS ONE Corporation, Osaka, Japan) to measure fluorescence. The fluorescent buffer $(78 \mu \mathrm{L})$, extraction solution $(30 \mu \mathrm{L})$ (the blank was set without a fluorescent buffer), and 0.03 $\mathrm{U} / \mu \mathrm{L}$ enzyme $(10 \mu \mathrm{L})$ were added to the samples (in this order) and then pre-incubated at $37^{\circ} \mathrm{C}$ for $10 \mathrm{~min}$. Next, $50 \mu \mathrm{M}$ substrate $(20 \mu \mathrm{L})$ was added to samples; samples were covered with Parafilm and then incubated at $37{ }^{\circ} \mathrm{C}$ for $2 \mathrm{~h}$. We measured absorbance values at $320 \mathrm{~nm}$ (excitation) and $405 \mathrm{~nm}$ (emission) using a fluorescent microplate reader (Grating Based Multimode Reader SH-9000: CORONA ELECTRIC Co, Ltd. Ibaragi, Japan). The enzyme concentration was $0.03 \mathrm{U}$ for rice bran and $0.015 \mathrm{U}$ for brown rice bread and commercial feed samples.

\section{Measurement of Hydrophilic and Lipophilic Oxygen Radical Absorbance Capacity}

We measured hydrophilic and lipophilic oxygen radical absorbance capacities (H-ORAC, L-ORAC) of rice samples as described by Prior et al. [42], Ito et al. [43], and Watanabe et al. $[44,45]$. For the hydrophilic antioxidant assay, we extracted freezedried rice samples $(0.1 \mathrm{~g})$ with $10 \mathrm{~mL}$ of hexane at room temperature for $2 \mathrm{~min}$ and then centrifuged the extract at $3000 \times \mathrm{g}$ for $15 \mathrm{~min}$. The hexane layer was removed, and we repeated the process. Residual hexane was evaporated using a water bath at $70^{\circ} \mathrm{C}$ for 10 $\mathrm{min}$, and then the residue was extracted with $10 \mathrm{~mL}$ of acetone/ water/acetic acid (70:29.5:0.5, v/v/v). Thereafter, the solution was sonicated (Ultrasonic cleaner 3510J-MTH: Branson Ultrasonics Co, Ltd. Kanagawa, Japan) at $37{ }^{\circ} \mathrm{C}$ for $15 \mathrm{~min}$. The tube remained at room temperature for $15 \mathrm{~min}$ and then was centrifuged at $3000 \times$ $\mathrm{g}$ for $15 \mathrm{~min}$. The supernatant was removed and transferred to a volumetric flask and diluted to $25 \mathrm{~mL}$ total volume. For the lipophilic antioxidant assay, freeze-dried rice samples $(0.1 \mathrm{~g})$ were extracted with $1 \mathrm{~mL}$ of hexane at room temperature for $2 \mathrm{~min}$ and then centrifuged at $3000 \times \mathrm{g}$ for $15 \mathrm{~min}$. The hexane layer was collected, and the process was repeated. The hexane was evaporated using a water bath at $70^{\circ} \mathrm{C}$ for $10 \mathrm{~min}$.

Then, the dried hexane extract was dissolved in $250 \mu \mathrm{L}$ of acetone and diluted with $750 \mu \mathrm{L}$ of $7 \%$ randomly methylated $\beta$-cyclodextrin (RMCD) (SIGMA Chemical Co. Tokyo, Japan) (i.e., 0.7 $\mathrm{g}$ of methyl- $\beta$-cyclodextrin was dissolved in $10 \mathrm{~mL}$ of $50 \%$ acetone). We prepared Trolox calibration solutions $(50,25,12.5$, and 6.25 $\mu \mathrm{mol} / \mathrm{L}$ in an assay buffer solution) to obtain a standard curve. We used a 96-well-plate microplate (AS ONE Corporation Osaka, Japan) to read fluorescence of samples. We measured absorbance values at $485 \mathrm{~nm}$ (excitation) and $530 \mathrm{~nm}$ (emission) using a fluorescent microplate reader (Grating Based Multimode Reader SH-9000: CORONA ELECTRIC Co, Ltd. Ibaragi, Japan). The Trolox calibration solutions, blank (dilute buffer), and diluted test samples $(35 \mu \mathrm{L})$, fluorescein solution $(115 \mu \mathrm{L}, 110.7 \mathrm{nmol} / \mathrm{L})$, and AAPH [2,2'-azobis (2-amidinopropane) dihydrochloride] solution $(50 \mu \mathrm{L}$, $31.7 \mathrm{mmol} / \mathrm{L}:$ H-ORAC, $63.4 \mathrm{mmol} / \mathrm{L}: \mathrm{L}-\mathrm{ORAC})$. Measurements were performed immediately at $37^{\circ} \mathrm{C}$ for $90 \mathrm{~min}$.

\section{Measurement of Plasma Concentrations of Aß1-42 And Aß1-40}

Plasma concentrations of $A \beta 1-42$ and $A \beta 1-40$ were analyzed using V-PLEX A $\beta$ Peptide Panel 1 (6E10) Kit (Meso Scale Discovery, Rockville, MD, USA) with MESO QuickPlex SQ 120 (Meso Scale Diagnostics, LLC, Rockville, MD, USA) according to the manufacturer's instruction. Intra-assay and inter-assay coefficients of variation were less than $20 \%$ for all assays.

\section{Study Design}

The study protocol for human test subjects was approved by the ethics committee for human tests of the Niigata Bio-research Park and Niigata University of Pharmacy and Applied Life Sciences and according to the 2014 guidelines issued by the Ministry of Education, Culture, Sports, Science, and Technology and the Ministry of Health, Labor, and Welfare, Japan. The test is registered as UMIN000030710. We recruited 36 normal, healthy human subjects 
(13 male, 23 female) for the study: fasting blood sugar level 78-119 $\mathrm{mg} / \mathrm{dL}($ mean $=101.94 \mathrm{mg} / \mathrm{dL})$ and body mass index 15.5-27.3 $\mathrm{kg} / \mathrm{m}^{2}$ (mean $\left.=21.4 \mathrm{~kg} / \mathrm{m}^{2}\right)$, grouped into three blocks. Subjects of each block ate the assigned test sample meals containing $50 \mathrm{~g}$ of carbohydrates once every day for 12 weeks consecutively. Subjects chose any other meals for two meals every day. After $0,6,12$ weeks, test subjects got the single-dose test for BGL measurements, where they consumed the assigned meals within $10 \mathrm{~min}$ with frequent mastication (30 times was the guideline) and $200 \mathrm{~mL}$ of water. BGL and insulin levels were measured at $0,30,60,90$, and 120 min after three groups of 12 subjects had eaten three different test meals. Blood samples were acquired (in February and March of 2018) from each subject for analysis of $A \beta 40, A \beta 42$, HDL cholesterol, LDL cholesterol, and insulin sensitivity. BFP was measured with a body composition meter (DC-320 separate type, TANITA Co., Ltd., Tokyo, Japan) using the impedance method.

\section{Statistical Analyses}

All results were subjected to t-tests and Dunnett's test using Excel Statistics (ver. 6, Microsoft Corporation, Tokyo, Japan). A value of $p<0.1$ was considered to show the tendency, and a value of $\mathrm{p}<0.05$ was considered to be statistically significant.

Table 1: Nutrient intakes and structural components of test-meals.

\begin{tabular}{|c|c|c|c|}
\hline & Control & Test Meal-1 & Test Meal-2 \\
\hline & Koshihikari Polished Cooked Rice & HPT KBH Cooked Rice & HPT KWB Cooked Rice \\
\hline Dietary intake (g) & 151.0 & 139.0 & 168.0 \\
\hline Carbohydrate (g) & 50.0 & 50.0 & 50.0 \\
\hline Dietary fiber (g) & 0.5 & 2.1 & 4.6 \\
\hline$\beta$-Glucan(g) & 0.3 & 0.3 & 2.9 \\
\hline Protein(g) & 2.9 & 4.2 & 4.5 \\
\hline Lipid(g) & 0.5 & 2.2 & 0.8 \\
\hline Sodium(mg) & 6.8 & 6.9 & 5.0 \\
\hline Anthocyanin(g) & 0.0 & 0.2 & 0.0 \\
\hline Moisture(g) & 98.0 & 83.0 & 112.0 \\
\hline Calorific value & 228.0 & 225.0 & 227.0 \\
\hline
\end{tabular}

Dietary fiber: enzymatic-gravimetric method ( Proskyvariant)

$\beta$-glucan: Official method of AOAC using an $\beta$-glucan assay kit (Megazyme Ltd., Wicklow, Ireland).

Protein: Kjeldahl method.

Lipid: Gas chromatography.

Sodium: Inductively coupled plasma atomic emission spectrometry.

Anthocyanin: HPLC method.

Moisture: Drying method by heating.

Calorific value: $(\mathrm{kcal} / 100 \mathrm{~g})=4 \mathrm{kcal} \times$ Protein $+9 \mathrm{kcal} \times$ Lipid $+4 \mathrm{kcal} \times$ Carbohydrate $+2 \mathrm{kcal} \times$ Dietary fiber

Test meal-1: "Koshihikari" unpolished rice, black unpolished rice "Okunomurasaki", and unpolished super-hard rice "Chikushikona 85", and polished super-hard rice "Goami 2" blended at a ratio of 2:4:2:2 and cooked after high-pressure-treatment (HPT).

Test meal-2: HPT KWB rice: polished rice “Koshihikari”, $\beta$-glucaSn-rich waxy hull-less barley, “Haneumamochi” blendedin a ratio of 5:5 and cooked after a high-pressure-treatment (HPT).

Control meal:“Koshihikari” polished cooked rice.

\section{Results and Discussion}

\section{Nutrient Intake and Structural Components of Test Meals}

Table $1 \beta$-glucan can reduce serum concentrations of total and LDL cholesterol [46] but the mechanism behind this reduction is unclear. However, it is difficult to predict the cholesterol-lowering effect of any particular food product enriched with $\beta$-glucan. [46] The Food and Drug Administration (FDA) of USA has stated that daily intakes of $3 \mathrm{~g}$ or more of soluble fiber ( $\beta$-glucan) in barley may reduce the risk of heart disease due to its ability to lower total and LDL cholesterol. [47] Aoe et al. showed that the intake of high $\beta$-glucan barley ( $4.4 \mathrm{~g} / \mathrm{d}$ ) leads to significant and safe reductions in visceral fat area (VFA), body weight, BMI, and waist circumference (WC) for 12-wk. [46] $\beta$-glucan content was 9.7-fold higher in cooked HPT KWB rice diet $(2.9 \mathrm{~g} / \mathrm{d})$ than in the cooked control rice diet and the HPT KBH cooked rice diet $(0.3 \mathrm{~g} / \mathrm{d})$ diets (Table 1). $\beta$-glucan content and dietary fiber showed a similar tendency in response to diet treatment effects. In contrast, lipid content was 4.4-fold higher in cooked HPT KBH rice diet $(2.2 \mathrm{~g} / \mathrm{d})$ than in the cooked control diet $(0.5 \mathrm{~g} / \mathrm{d})$. In addition, the HPT KBH rice diet showed high anthocyanin values $(0.2 \mathrm{~g} / \mathrm{d})$. 
Changes in Physical Findings and Blood Inspection Values of Three Groups of Test Subjects

Murao et al. [48]. showed that the LDL-to-HDL cholesterol ratio was 2.24 in subjects not being treated for diabetes mellitus, hypertension, or dyslipidemia, and that the ratio of subjects with no traditional cardiovascular risk factors (BMI, blood pressure, fasting blood glucose, HbA1c, HDL, LDL cholesterol , triglyceride, and uric acid levels below ideal levels) was 1.46. In comparison, after 12 weeks of test subjects following their assigned diets in our study, we determined that test subjects had LDL-to-HDL cholesterol ratio of 1.9 [SD (standard deviation): 0.8 ] for control diet subjects, 2.0 (SD: 0.5) for HPT KBH diet subjects, and 2.0 (SD: 0.8) for HPT KWB diet subjects (Table 2). Table 2 summarizes the effects of the intervention on the measured anthropometric and serum biochemical parameters. During the trial, body weight and BMI did not show significant difference among the three groups. As a result, the HPT KBH and HPT KWB diets had no effect on total or LDL cholesterol after 12 weeks following the diet.

Table 2: Changes in physical parameters and blood inspection values of the three test diets Changes in physical findings and blood inspection value of the test diet three groups of test subjects.

\begin{tabular}{|c|c|c|c|c|}
\hline ParameterD7D7:H34 & Test diet group & Baseline & After 6-wk & After 12-wk \\
\hline \multirow{3}{*}{ Body fat (\%) } & Control meal & $30.0 \pm 7.4$ & $29.2 \pm 8.2$ & $30.2 \pm 7.9$ \\
\hline & Test meal-1 & $25.8 \pm 8.0$ & $24.9 \pm 8.1$ & $25.3 \pm 7.4$ \\
\hline & Test meal-2 & $26.2 \pm 6.6$ & $24.3 \pm 6.6$ & $24.8 \pm 6.3$ \\
\hline \multirow{3}{*}{ Body weight (kg) } & Control meal & $58.0 \pm 5.8$ & $57.7 \pm 5.8$ & $58.3 \pm 6.2$ \\
\hline & Test meal-1 & $54.9 \pm 8.6$ & $54.7 \pm 8.9$ & $55.1 \pm 9.2$ \\
\hline & Test meal-2 & $58.3 \pm 12.3$ & $57.5 \pm 11.6$ & $58.0 \pm 11.6$ \\
\hline \multirow{3}{*}{ BMI (Body mass index $)\left(\mathrm{kg} / \mathrm{m}^{2}\right)$} & Control meal & $22.1 \pm 2.1$ & $22.0 \pm 2.120$ & $22.3 \pm 2.2$ \\
\hline & Test meal-1 & $20.5 \pm 3.4$ & $20.4 \pm 3.6$ & $20.5 \pm 3.7$ \\
\hline & Test meal-2 & $21.3 \pm 2.8$ & $20.9 \pm 2.7$ & $21.1 \pm 2.7$ \\
\hline \multirow{3}{*}{ Pulse bpm, beats per min } & Control meal & $67.5 \pm 10.9$ & $69.5 \pm 12.6$ & $64.4 \pm 7.5$ \\
\hline & Test meal-1 & $67.7 \pm 9.3$ & $69.9 \pm 11.5$ & $63.6 \pm 7.2$ \\
\hline & Test meal 2 & $66.7 \pm 11.0$ & $70.2 \pm 9.0$ & $65.1 \pm 11.1$ \\
\hline \multirow{3}{*}{ Systolic blood pressure (mmHg) } & Control meal & $123.0 \pm 15.2$ & $121.3 \pm 16.1$ & $118.6 \pm 13.7$ \\
\hline & Test meal-1 & $120.0 \pm 13.6$ & $119.7 \pm 13.9$ & $111.9 \pm 11.8$ \\
\hline & Test meal-2 & $121.3 \pm 17.4$ & $118.0 \pm 15.4$ & $113.8 \pm 12.8$ \\
\hline \multirow{3}{*}{ Diastolic blood pressure (mmHg) } & Control meal & $74.9 \pm 11.8$ & $74.0 \pm 13.2$ & $72.1 \pm 12.3$ \\
\hline & Test meal-1 & $71.5 \pm 11.6$ & $72.0 \pm 9.8$ & $67.0 \pm 11.5$ \\
\hline & Test meal-2 & $73.3 \pm 14.6$ & $74.1 \pm 10.5$ & $67.5 \pm 9.3$ \\
\hline \multirow{3}{*}{ Triglyceride $[\mathrm{mg} / \mathrm{dL}]$} & Control meal & $71.8 \pm 36.56$ & $76.4 \pm 50.0$ & $78.6 \pm 45.6$ \\
\hline & Test meal-1 & $69.1 \pm 19.3$ & $73.0 \pm 23.4$ & $81.3 \pm 23.3$ \\
\hline & Test meal-2 & $71.8 \pm 29.0$ & $72.8 \pm 30.0$ & $82.3 \pm 23.5$ \\
\hline \multirow{3}{*}{ LDL-Cholesterol [mg/dL] } & Control meal & $71.8 \pm 29.0$ & $128.3 \pm 38.2$ & $131.0 \pm 38.9$ \\
\hline & Test meal-1 & $107.2 \pm 20.7$ & $111.6 \pm 19.6$ & $112.6 \pm 19.1$ \\
\hline & Test meal-2 & $106.5 \pm 21.0$ & $109.7 \pm 25.4$ & $117.0 \pm 29.2$ \\
\hline \multirow{3}{*}{ HDL-Cholesterol [mg/dL] } & Control meal & $74.5 \pm 15.8$ & $74.6 \pm 15.0$ & $71.9 \pm 14.9$ \\
\hline & Test meal-1 & $61.7 \pm 10.3$ & $59.9 \pm 12.0$ & $57.4 \pm 11.2^{*}$ \\
\hline & Test meal-2 & $67.2 \pm 15.3$ & $64.4 \pm 15.0$ & $63.9 \pm 13.8$ \\
\hline \multirow{3}{*}{ Urea nitrogen [mg/dL] } & Control meal & $1 \mathrm{~S} 2.5 \pm 2.4$ & $12.7 \pm 2.0$ & $12.4 \pm 3.6$ \\
\hline & Test meal-1 & $12.8 \pm 2.9$ & $12.7 \pm 3.8$ & $12.2 \pm 2.8$ \\
\hline & Test meal-2 & $11.5 \pm 1.6$ & $13.6 \pm 3.1$ & $12.6 \pm 2.6$ \\
\hline \multirow{3}{*}{ Total protein $[\mathrm{g} / \mathrm{dL}]$} & Control meal & $7.3 \pm 0.5$ & $7.4 \pm 0.3$ & $7.3 \pm 0.3$ \\
\hline & Test meal-1 & $7.3 \pm 0.3$ & $7.3 \pm 0.3$ & $7.1 \pm 0.3$ \\
\hline & Test meal-2 & $7.0 \pm 0.2$ & $7.1 \pm 0.2$ & $7.2 \pm 0.3$ \\
\hline
\end{tabular}

Control meal (3 male: 9 female), test meal-1 ( 4 male: 8 female), and test meal-2 (6 male: 6 female) *; significant by the Dunnett's test $(\mathrm{p}<0.05)$. 


\section{Physical Properties of Cooked Rice}

Cooked grains of ae-mutant rice cultivars are hard and nonsticky because they lack the starchbranching enzyme IIb and contain more SLCs. Ae-mutant grains appear to provide promising health benefits, such as diabetes prevention $[7,8]$. The physical properties of cooked rice, measured in bulk using a Tensipresser, detected differences among rice varieties in hardness, toughness, degree of adhesion, and stickiness, all important indices when evaluating rice palatability [41], with toughness showing similar tendencies as hardness. "Chikushi-kona 85" rice was the hardest and toughest among all samples tested, but it was also the least sticky and least adhesive (Table 3a). As a result, cooked grains of the ae-mutant brown rice cultivar are too hard and non-sticky to be marketed as table rice. Moreover, the hardness and toughness of the unpolished rice "Chikushi-kona 85" and polished rice "Goami2" were reduced 0.9-fold after HPT, whereas the adhesion and stickiness of black, unpolished rice were increased 3.3-fold and 2.4-fold after HPT, respectively (relative to the control). Furthermore, the hardness, toughness, adhesiveness, and stickiness for the waxy barley cultivar "Haneumamochi" increased by 1.2 -fold after HPT relative to the untreated control (data not shown). We show that HPT treatment should make ae-mutant unpolished rice and black unpolished rice acceptable to consumers as table rice, after cooking. Therefore, HPT would be very beneficial to the rice industry due to the physical improvements HPT affords unpolished rice.

The hardness value of kernels was 4.8-fold higher in cooked HPT KBH rice than cooked rice of the control diet ("Koshihikari" polished rice). Toughness values were positively related to hardness, whereas adhesion was positively related to stickiness (Table 3b). However, the stickiness was 0.3-fold lower in cooked HPT KBH and HPT KWB rice than in cooked rice of the control diet. The polished waxy barley contained starch that was 97\%-100\% amylopectin; [49], for that reason, the hardness and toughness for HPT KWB rice were similar to the control rice diet.

Table 3: Physical properties of individual material rice and blend rice by HPT and untreated cooked rice.

Table 3a:

\begin{tabular}{|c|c|c|c|c|c|c|c|c|c|c|c|c|}
\hline & $\begin{array}{l}\text { Hardness } \\
{\left[\mathrm{gw} / \mathrm{cm}^{2}\right]}\end{array}$ & \multicolumn{2}{|c|}{ SD } & $\begin{array}{l}\text { Toughness } \\
{\left[\mathrm{gw} / \mathrm{cm}^{2}\right]}\end{array}$ & \multicolumn{2}{|c|}{ SD } & $\begin{array}{l}\text { Adhesion } \\
{\left[\mathrm{gw} / \mathrm{cm}^{2}\right]}\end{array}$ & \multicolumn{2}{|c|}{ SD } & $\begin{array}{l}\text { Stickiness } \\
{\left[\mathrm{gw} / \mathrm{cm}^{2}\right]}\end{array}$ & \multicolumn{2}{|c|}{ SD } \\
\hline Koshihikari brown rice & 13.4 & $\mathrm{a}$ & 4.5 & 22.9 & $\mathrm{a}$ & 1 & 43.1 & $\mathrm{a}$ & 2.8 & 17.1 & $\mathrm{a}$ & 1.2 \\
\hline Okunomurasaki brown rice & 25 & $\mathrm{~b}$ & 0.7 & 28.3 & $\mathrm{a}$ & 1.2 & 6.5 & $\mathrm{~b}$ & 1.5 & 4.3 & $\mathrm{~b}$ & 0.1 \\
\hline Chikushi-kona85' brown rice & 96.6 & c & 17.8 & 38.3 & $\mathrm{~b}$ & 0.4 & 0.3 & $\mathrm{~d}$ & 0 & 0.1 & $\mathrm{c}$ & 0 \\
\hline Goami2 white rice & 14.3 & $\mathrm{a}$ & 1 & 19.3 & $\mathrm{a}$ & 0.8 & 2.7 & $\mathrm{~b}$ & 0.4 & 2.8 & $\mathrm{~b}$ & 1.5 \\
\hline $\begin{array}{c}\text { Koshihikari brown rice } \\
\text { (HPT) }\end{array}$ & 16.6 & $\mathrm{a}$ & 2 & 26.5 & $\mathrm{a}$ & 3 & 8.9 & $\mathrm{~b}$ & 1 & 9.2 & $\mathrm{~b}$ & 0.6 \\
\hline $\begin{array}{c}\text { Okunomurasaki brown rice } \\
\text { (HPT) }\end{array}$ & 22.2 & $\mathrm{~b}$ & 0.2 & 24 & a & 1.5 & 21.4 & c & 1.5 & 10.2 & $\mathrm{a}$ & 1.2 \\
\hline $\begin{array}{c}\text { Chikushi-kona } 85 \text { ' brown } \\
\text { rice (HPT) }\end{array}$ & 86.9 & $\mathrm{c}$ & 16 & 34.5 & $\mathrm{~b}$ & 0.3 & 0.2 & $\mathrm{~d}$ & 0 & 0.1 & $\mathrm{c}$ & 0 \\
\hline Goami2 white rice (HPT) & 12.9 & $\mathrm{a}$ & 4 & 16.3 & $\mathrm{a}$ & 1 & 3.4 & $\mathrm{~b}$ & 0.6 & 2.4 & $\mathrm{~b}$ & 0.6 \\
\hline
\end{tabular}

Table 3b:

\begin{tabular}{|c|c|c|c|c|c|c|c|c|c|c|c|c|}
\hline & $\begin{array}{c}\text { Hardness [gw/ } \\
\mathbf{c m}^{2} \text { ] }\end{array}$ & \multicolumn{2}{|c|}{ SD } & $\begin{array}{c}\text { Toughness [gw/ } \\
\mathbf{c m}^{2} \text { ] }\end{array}$ & \multicolumn{2}{|c|}{ SD } & $\begin{array}{c}\text { Adhesion [gw/ } \\
\mathbf{c m}^{2} \text { ] }\end{array}$ & \multicolumn{2}{|c|}{ SD } & $\begin{array}{c}\text { Stickiness[gw/ } \\
\mathbf{c m}^{2} \text { ] }\end{array}$ \\
\hline Control diet & 6.5 & $\mathrm{a}$ & 0.4 & 25.8 & $\mathrm{a}$ & 1.9 & 30.4 & $\mathrm{a}$ & 7.3 & 43.5 & $\mathrm{a}$ & 11.2 \\
\hline HPT KWB & 9.9 & $\mathrm{~b}$ & 3.2 & 27.6 & $\mathrm{a}$ & 4.2 & 7.7 & $\mathrm{a}$ & 3.7 & 19 & $\mathrm{a}$ & 8.3 \\
\hline HPT KBH & 31 & $\mathrm{c}$ & 7.2 & 41.6 & $\mathrm{~b}$ & 3.1 & 7.8 & $\mathrm{~b}$ & 1.3 & 17.6 & $\mathrm{~b}$ & 2.1 \\
\hline
\end{tabular}

Means with the same letter are not significantly different $(\mathrm{p}<0.05)$. Control meal: "Koshihikari" polished cooked rice.

HPT KBH rice: unpolished rice “Koshihikari”, black unpolished rice, “Okunomurasaki”, un-polishe super-hard rice, “Chikushkona85' " and polished super-hard rice, "Goami 2 " blended in a ratio of 2:4:2:2 and cooked after a high-pressure-treatment (HPT). HPT KWB rice: polished rice "Koshihikari", $\beta$-glucan-rich waxy hull-less barley, "Haneumamochi" blendedin a ratio of 5:5 and cooked after a 797 high-pressure-treatment (HPT).

\section{Measurement of Iodine Absorption Spectra}

Starch properties measured by the iodine colorimetric method is shown in Table 4. AAC is an effective parameter for estimating the cooking or eating quality of rice grains. Because ae-mutants lack the starch-branching enzyme IIb, its amylopectin contains more longchain glucans than does ordinary indica and japonica rice grains.
[50-53] AAC concentration values for ae-rice cultivars "Chikushikona 85" (28.5\%) and "Goami2" (35.1\%) were higher than those of typical japonica rice cultivar "Koshihikari" (12.1\%) and black rice "Okunomurasaki" (12.1\%). The high molecular weight amyloses in ae-mutant cultivars tend to have a higher value for $\lambda \max , A \lambda \max$, New $\lambda$ max, and Fb3 (the proportion of amylopectin with longer 
chains) (DP $\geq 37$ ) [40], indicating that rice with high $\lambda \max / A \lambda \max$ ratios are palatable [40]. The $\lambda \max / A \lambda \max$ ratios for "Chikushikona 85" (1082.1) and "Goami2" (1049.9) were lower than ratios for "Koshihikari" (2189.3) and "Okunomurasaki" (2257.7). Furthermore, AAC concentration values for "Chikushi-kona 85" (18.3\%) (pretreated with HPT) was $60 \%$ that of the control $(28.5 \%)$ rice. The AAC values for the other samples (pretreated with HTP) showed almost the same values as the control samples.
Furthermore, the $A \lambda \max$, New $\lambda$ max, and Fb3 (DP $\geq 37$ ) values for "Chikushi-kona 85" (pretreated with HTP) values were $80 \%$ of the control. The A $\lambda$ max, New $\lambda \max$, and Fb3 (DP $\geq 37$ ) values for other samples (pretreated with HTP) showed almost the same values as the control samples, whereas the $\lambda$ max/A $\lambda$ max ratios for all samples (pretreated with HTP) were 1.02-1.26 times higher than control samples. It appears from these data that pretreating rice with HPP renders the starch component of rice grains more palatable.

Table 4: Analyses of iodine absorption curve and glucose content of individual material rice by HPT and untreated rice.

Table 4a:

\begin{tabular}{|c|c|c|c|c|c|c|c|c|c|c|c|c|c|c|c|c|c|c|}
\hline & $\begin{array}{l}\text { AAC } \\
\text { (\%) }\end{array}$ & & SD & $\begin{array}{l}\lambda \max \\
(\mathrm{nm})\end{array}$ & & SD & $A \lambda \max$ & & SD & $\begin{array}{l}\lambda \max / \\
A \lambda \max \end{array}$ & & SD & $\begin{array}{c}\text { New } \\
\lambda \max \end{array}$ & & SD & $\begin{array}{c}\text { Fb3 } \\
(\mathrm{DP} \geqq 37)\end{array}$ & & D \\
\hline $\begin{array}{l}\text { Koshihikari } \\
\text { brown rice }\end{array}$ & 12.1 & a & 0.2 & 561.5 & a & 0.7 & 0.257 & a & 0 & 2189.3 & $\mathrm{a}$ & 27.4 & 0.21 & a & 0 & 10.7 & a & 0.2 \\
\hline $\begin{array}{l}\text { Okunomurasaki } \\
\text { brown rice }\end{array}$ & 12.1 & a & 0.2 & 565.5 & a & 0.7 & 0.251 & a & 0 & 2257.7 & $a$ & 34.7 & 0.19 & a & 0 & 10.4 & a & 0.2 \\
\hline $\begin{array}{l}\text { Chikushi-kona } \\
85^{\prime} \text { brown rice }\end{array}$ & 28.5 & $\mathrm{~b}$ & 0.3 & 567 & a & 1.4 & 0.524 & $\mathrm{~b}$ & 0.006 & 1082.1 & $\mathrm{~b}$ & 14.4 & 0.65 & $\mathrm{~b}$ & 0.03 & 22.6 & $\mathrm{~b}$ & 0.3 \\
\hline $\begin{array}{l}\text { Goami2 white } \\
\text { rice }\end{array}$ & 35.1 & c & 0.1 & 579 & b & 1.4 & 0.552 & b & 0.006 & 1049.9 & $\mathrm{~b}$ & 1.5 & 0.57 & $\mathrm{~b}$ & 0.01 & 23.9 & $\mathrm{~b}$ & 0.1 \\
\hline $\begin{array}{c}\text { Koshihikari } \\
\text { brown rice (HPT) }\end{array}$ & 11.1 & $\mathrm{a}$ & 0.2 & 559 & a & 1.4 & 0.245 & a & 0 & 2286.4 & $a$ & 25.6 & 0.19 & a & 0.01 & 10.2 & $\mathrm{a}$ & 0.1 \\
\hline $\begin{array}{c}\text { Okunomurasaki } \\
\text { brown rice (HPT) }\end{array}$ & 12 & $\mathrm{a}$ & 0.1 & 570.5 & $\mathrm{~b}$ & 3.5 & 0.247 & $\mathrm{a}$ & 0 & 2309.7 & $a$ & 1.1 & 0.18 & a & 0.01 & 10.3 & $\mathrm{a}$ & 0.1 \\
\hline
\end{tabular}

Table 4b:

\begin{tabular}{|c|c|c|c|}
\hline & Glucose Content (G/100g) & SD \\
\hline Koshihikari brown rice (HPT) & 0.03 & a & 0.001 \\
\hline Okunomurasaki brown rice (HPT) & 0.07 & b & 0.001 \\
\hline Chikushi-kona 85' brown rice (HPT) & 0.18 & c & 0.006 \\
\hline Goami2 white rice (HPT) & 0.284 & d & 0.005 \\
\hline Haneumamochi & 0.23 & d & 0.001 \\
\hline
\end{tabular}

Changes in Postprandial BGL, Insulin Levels, Area Under the Curve (AUC), And the Insulin Rise Curve (AUCi) In Humans

Panlasigui and Thompson [54] showed that unpolished rice is healthier and more beneficial than polished rice for diabetics and hyperglycemic individuals and that the glycemic area and GI were $35.4 \%$ lower in unpolished rice than in polished rice. Jung et al. [55] showed that ferulic acid might be beneficial in the treatment of type- 2 diabetes because it regulates BGLs by elevating glucokinase activity and the production of glycogen in the liver. The BGL of test subjects $30 \mathrm{~min}$ after ingesting cooked HPT KBH (test meal-1) showed lower tendency after 12 weeks on the diets than that in subjects who consumed the control diet $(\mathrm{p}<0.1)$, and that of cooked HPT KWB (test meal-2) was significantly lower than that of control $\operatorname{diet}(\mathrm{p}<0.01)$ (Figure 1A), whereas AUC showed a similar tendency in response to diet after 30 and 60 min (Figure 1B). After 12 weeks on treatment diets, insulin levels of test subjects that ingested cooked HPT KBH rice (test meal 1) were significantly lower at 120 min after the meal than insulin levels in subjects consuming the control diet $(\mathrm{p}<0.05)$ (Figure 2A). Furthermore, after 12 weeks on their assigned diets, AUCi in test subjects at 90 and $120 \mathrm{~min}$ after ingesting the cooked HPT KWB (test meal 2) showed lower tendency than those in test subjects who ingested the control diet $(\mathrm{p}<0.1$, Figure 2B). 
(A)

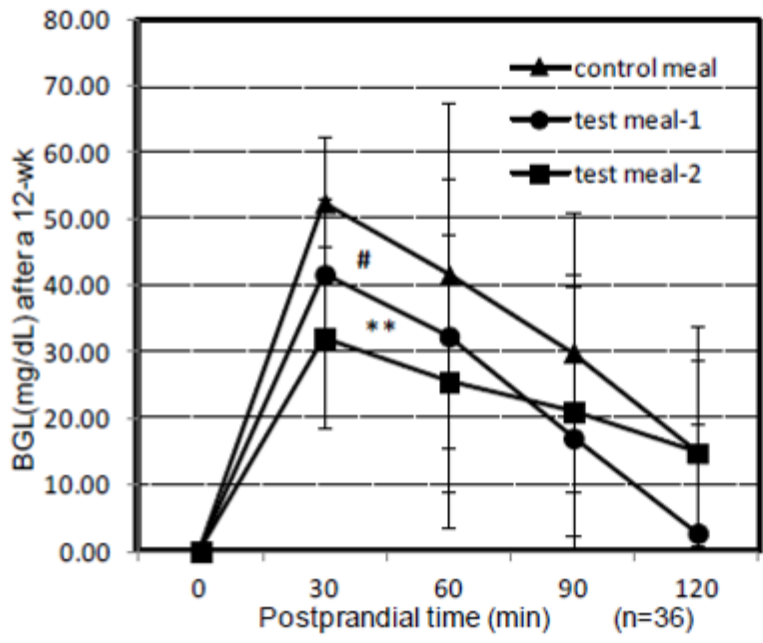

(B)

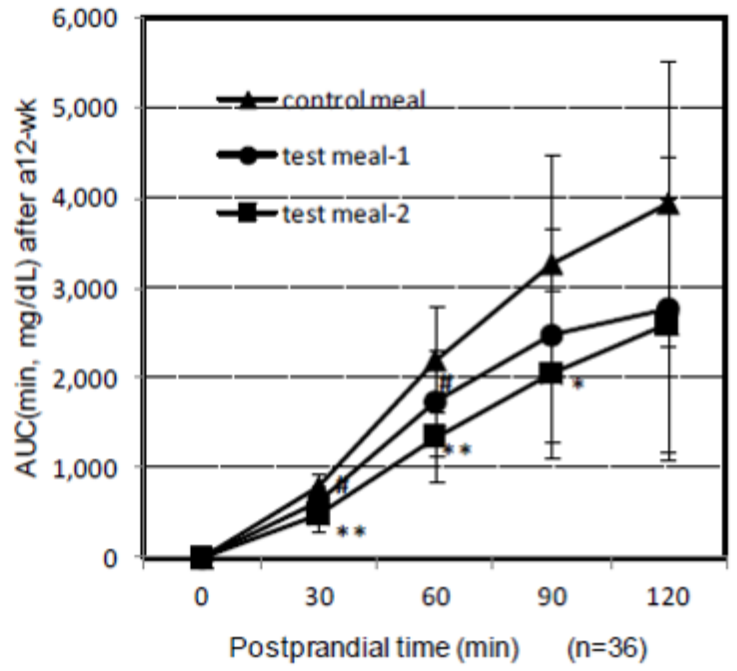

${ }^{*}, \mathrm{p}<0.05,{ }^{* *}, \mathrm{p}<0.01, \#, \mathrm{p}<0.1$

Figure 1: Changes in the BGL and AUC in 36 subjects after eating HPT KBH and KWB cooked rice after a 12-wk.

(A)

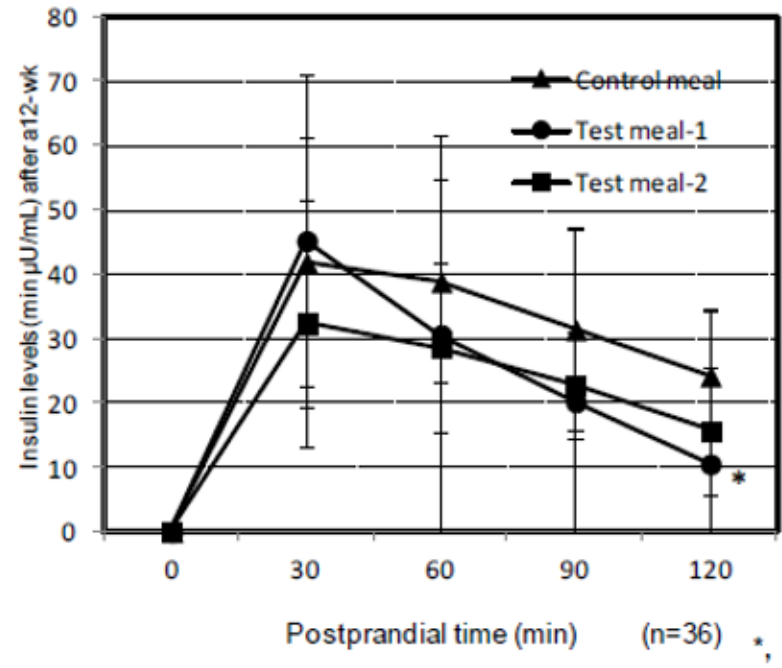

(B)

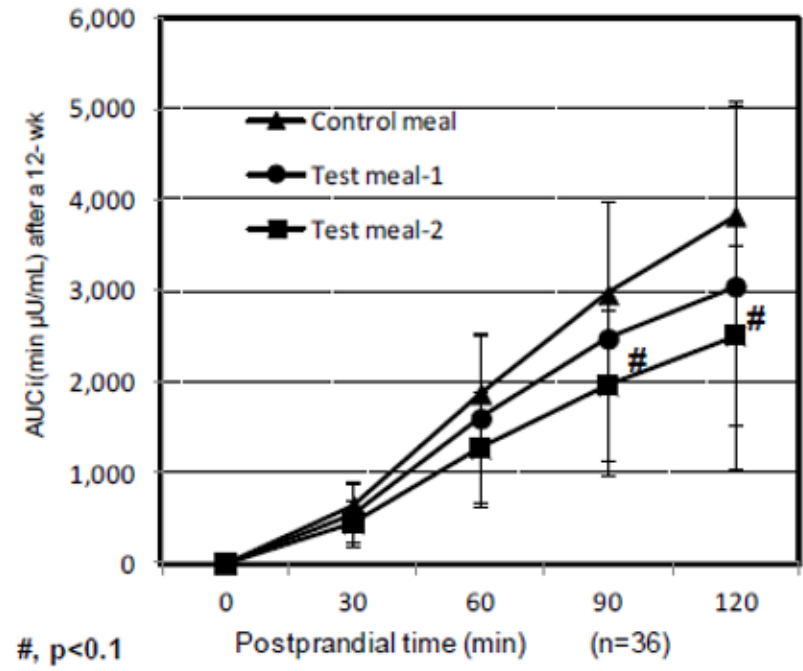

Figure 2: Changes in the insulin levels and AUCi in 36 subjects after eating HPT KBH and HPT KWB cooked rice after a 12-wk.

\section{RS Contents of Samples}

RS is starch that eludes digestion in the small intestine and may ferment in the large intestine. Several studies have reported that long-term consumption of RS might reduce fasting cholesterol and triglyceride concentrations. [19-21] Reader et al. [56] showed that $7.25 \mathrm{~g} / \mathrm{d}$ of RS added to an energy bar reduced blood glucose and insulin levels in healthy adults. The RS contents of the "Goami2" (9.8\%) and "Chikushi-kona 85" (10.2\%) were very high (i.e., 44.3- 46.3-fold higher than RS in "Koshihikari" unpolished rice (0.2\%) (Table 5). RS contents for "Koshihikari" unpolished rice, "Chikushikona 85" unpolished rice, and "Haneumamochi" were 1.5-fold and 1.2-fold higher (relative to the control), respectively, after HPT (200 MPa for 2 min). RS content was 2.4 -fold higher $(\mathrm{P}<0.05)$ in cooked HPT KBH rice $(2.9 \%)$ than in the cooked control rice $(1.2 \%)$ (Table 7). In contrast, RS content was 0.8 -fold lower in the cooked HPT $\mathrm{KWB}$ rice than in the cooked control rice diet. 
Table 5: Resistant starch of individual material rice by HPT and untreated cooked rice.

\begin{tabular}{|c|c|c|c|}
\hline & Resistant Starch (\%) & \multicolumn{2}{|c|}{ SD } \\
\hline Koshihikari brown rice & 0.2 & a & 0 \\
\hline Okunomurasaki brown rice & 0.3 & a & 1 \\
\hline Chikushi-kona 85' brown rice & 10.2 & b & 0.5 \\
\hline Goami2 white rice & 9.8 & b & 0 \\
\hline Haneumamochi & 0.6 & a & 0 \\
\hline Koshihikari brown rice (HPT) & 0.3 & a & 0 \\
\hline $\begin{array}{c}\text { Okunomurasaki brown rice } \\
\text { (HPT) }\end{array}$ & 0.3 & a & 0 \\
\hline $\begin{array}{c}\text { Chikushi-kona 85' brown rice } \\
\text { (HPT) }\end{array}$ & 12 & b & 0.1 \\
\hline Goami2 white rice (HPT) & 9.9 & b & 0 \\
\hline Haneumamochi(HPT) & 0.7 & a & 0 \\
\hline
\end{tabular}

Means with the same letter are not significantly different $(\mathrm{p}<0.05)$.

Control meal: "Koshihikari" polished cooked rice.

HPT KBH rice: unpolished rice "Koshihikari", black unpolished rice, "Okunomurasaki", un-polishesuper-hard rice, "Chikushkona85" " and polished super-hard rice, "Goami2 " blended in a ratio of 2:4:2:2 and cooked after a high-pressuretreatment (HPT).

HPT KWB rice: polished rice "Koshihikari", $\beta$-glucan-rich waxy hull-less barley, "Haneumamochi" blendedin a ratio of 5:5 and cooked after a high-pressure-treatment (HPT).

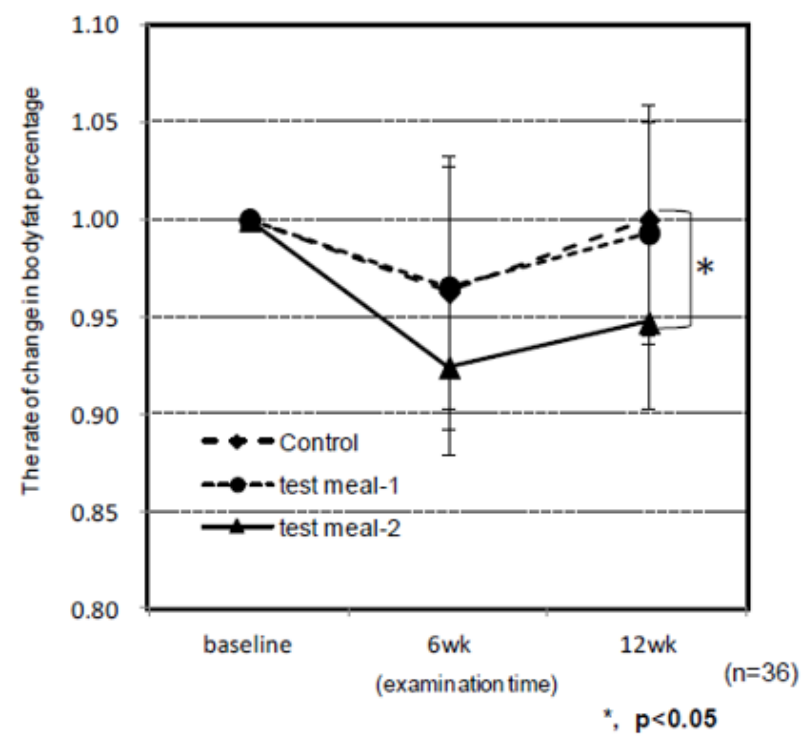

Figure 3: Changes in the body fat percentage after eating HPT KBH and KWB cooked rice after a 6-wk and a 12-wk.

\section{Changes in BFP Values for Three Groups of Meals}

Test subjects who consumed the HPT KWB rice blend diet had significantly lower BFP values than those who consumed the control $\operatorname{diet}(\mathrm{p}<0.05)$ after 12 weeks on the diet (Figure 3). Although HDL cholesterol level is a strong inverse predictor of cardiovascular events, it is not clear whether this association holds true when cholesterol is at a very low level $[55,57]$. Manninen et al. showed that the LDL-to-HDL cholesterol ratio was the best single predictor of cardiac events in a placebo group. This ratio, in combination with serum triglyceride level, indicates a high-risk for heart disease.

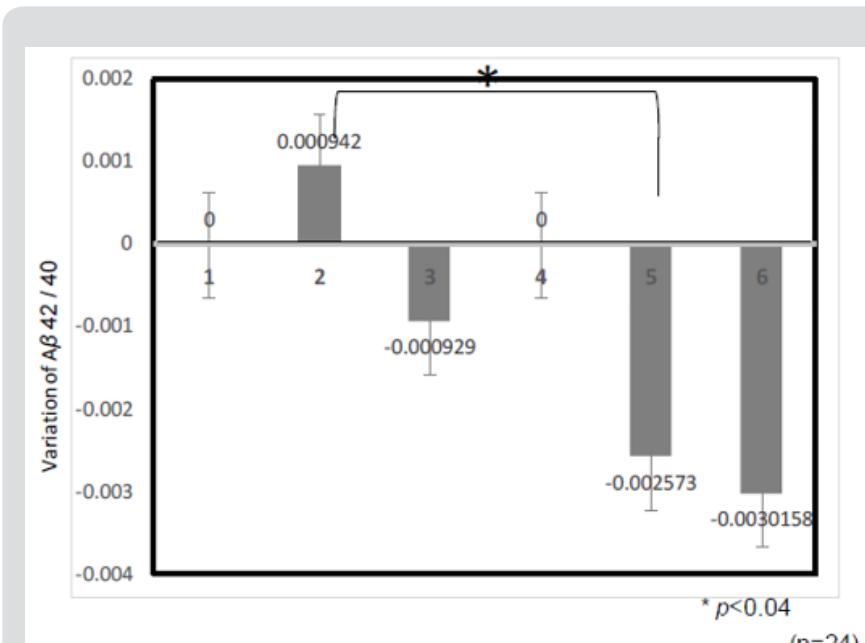

Figure 4: Changes of variation of amyloid $\beta-42 / 40$ peptide ratio by ELISA after a 6 -wk and a $12-w k$.

1, baseline (test meal-1), 2, 6 week (test meal-1), 3, 12 week (test meal-1), 4, baseline (control), 5, 6week (control), 6, 12 week (control)* $\mathrm{p}<0.04^{*}$. Changes of variation of amyloid $\beta-42 / 40$ peptide ratio by ELISA after a 6-wk and a 12-wk.Test meal-1: HPT KBH: blend of unpolished rice Koshihikari, Okunomurasaki,Chikushi-kona85' and of polished rice Goami2 (2:4:2:2) cooked after a high-pressure treatment.

\section{Changes in Variation of Amyloid $\beta 42 / 40$ Peptide Ratio Species}

Amyloid beta peptides $(A \beta)$ are important components of plaque in AD. Plasma concentration of $A \beta$ (1-40) and $A \beta$ (1-42) rise with age and are higher in people with mutations that cause early onset of AD. However, A $\beta$ (1-42) concentrations may decline early in the dementia process [59]. High plasma concentrations of $A \beta$ (1-40), especially when combined with low concentrations of $A \beta$ (1-42), indicate an increased risk of dementia [59,60]. Thus, plasma $A \beta 42 / 40$ ratio may be a useful premorbid biomarker for identifying cognitive deterioration [61]. Blood samples were taken from the 24 subjects after meals before diets began (baseline) and after 6 and 12 weeks on their assigned diets. Variation in $A \beta$ $42 / 40$ ratio after 6 weeks of consuming the HPT KBH rice diet $(0.0009)$ was significantly higher $(\mathrm{p}<0.04)$ than ratio for subjects consuming the control diet $(-0.0026)$ (Figure 4). Thus, changes in BACE1 inhibitory activity, due to consuming the HPT KBH rice diet over the long-term, might have played a role in lowering $A \beta$ ratios after meals.

\section{Measurement of Hydrophilic and Lipophilic Oxygen Radical Absorbance Capacity}

Many dietary compounds have been proposed as being important antioxidants, and although there is credible evidence 
that vitamins $\mathrm{E}$ and $\mathrm{C}$ are important antioxidants, evidence is weaker for carotenoids and related plant pigments [62]. L-ORAC values of "Koshihikari" unpolished rice, "Okunomurasaki" unpolished rice, "Chikushi-kona 85" unpolished rice, and "Goami2" polished rice increased markedly after HPT (Table 6). Therefore, HPT increases lipophilic antioxidant substances, except in the waxy barley ("Haneumamochi"). This lack of increase may have been due to damage to cell membranes organelles, such as spherosomes, which liberate or create free lipophilic antioxidants, such as tochopherol. Conversely, H-ORAC values in the unpolished black rice "Okunomurasaki" were much higher than in other samples. It seems that anthocyanin in unpolished black rice plays a principal role in
H-ORAC values because hydrophilic antioxidant anthocyanins react more effectively when subjected to HPT (200 MPa). L-ORAC for HPT KBH rice and HPT KWB rice increased 2.9-fold and 1.7-fold $(\mathrm{P}<0.05)$, respectively, relative to the control rice diet (Table 7). $\mathrm{H}$-ORAC values trended in similar directions to L-ORAC values in response to dietary treatment effects. Tsuda et al. [63] showed that anthocyanins extracted from purple corn prevented obesity and ameliorated hyperglycemia in mice. Moreover, Suzuki et al. [64]. showed that the calcium content of pigmented brown rice was higher than the "Koshihikari" cultivar. These experiments suggest that anthocyanins may function in helping prevent oxidation in vivo.

Table 6: H-ORAC and L-ORAC capacity of individual material rice by HPT and untreated cooked rice.

\begin{tabular}{|c|c|c|c|c|c|c|}
\hline \multirow[b]{2}{*}{ Koshihikari brown rice } & \multirow{2}{*}{$\begin{array}{c}\text { H-ORAC } \boldsymbol{\mu m o l} \text { TE/100gFW } \\
41.6\end{array}$} & \multicolumn{2}{|c|}{ SD } & \multirow{2}{*}{$\frac{\text { L-ORAC } \mu \mathrm{mol} \mathrm{TE} / 100 \mathrm{gFW}}{4.4}$} & \multicolumn{2}{|c|}{ SD } \\
\hline & & a & 1.8 & & a & 0 \\
\hline Okunomurasaki brown rice & 285.8 & a & 8.6 & 5.3 & $\mathrm{a}$ & 0 \\
\hline Chikushi-kona $85^{\prime}$ brown rice & 210.4 & $\mathrm{~b}$ & 5.2 & 1.3 & a & 0 \\
\hline Goami2 white rice & 252.6 & $\mathrm{~b}$ & 3.7 & 0.9 & a & 0 \\
\hline Haneumamochi & 59.1 & a & 2.8 & 17.5 & c & 0.8 \\
\hline Koshihikari brown rice (HPT) & 43.1 & a & 2.8 & 43 & a & 3.8 \\
\hline $\begin{array}{l}\text { Okunomurasaki brown rice } \\
\text { (HPT) }\end{array}$ & 361 & $\mathrm{~b}$ & 12.3 & 32.7 & a & 4 \\
\hline $\begin{array}{c}\text { Chikushi-kona 85' brown rice } \\
\text { (HPT) }\end{array}$ & 189 & c & 9.6 & 11.7 & $\mathrm{~b}$ & 1.8 \\
\hline Goami2 white rice (HPT) & 214.4 & c & 8.3 & 8.2 & $\mathrm{~b}$ & 2.8 \\
\hline Haneumamochi(HPT) & 50.5 & a & 3.8 & 11.1 & $\mathrm{~b}$ & 3.1 \\
\hline
\end{tabular}

Means with the same letter are not significantly different $(\mathrm{p}<0.05)$.

Control meal:"Koshihikari" polished cooked rice.

HPT KBH rice: unpolished rice “Koshihikari”, black unpolished rice, “Okunomurasaki”, un-polishesuper-hard rice, "Chikushkona85” " and polished super-hard rice, "Goami2" blended in a ratio of 2:4:2:2 and cooked after a high-pressure-treatment (HPT).

HPT KWB rice: polished rice "Koshihikari", $\beta$-glucan-rich waxy hull-less barley, "Haneumamochi" were blended in a ratio of 5:5 and cooked after a high-pressure-treatment (HPT).

Table 7: Bio-functional properties of blended cooked samples.

\begin{tabular}{|c|c|c|c|c|c|c|c|c|c|c|c|c|c|c|c|}
\hline & $\begin{array}{l}\text { Resistant } \\
\text { starch }\end{array}$ & & & $\begin{array}{c}\text { H-ORAC } \\
\mu \mathrm{mol}\end{array}$ & & & L-ORAC $\mu \mathrm{mol}$ & & & $\begin{array}{l}\text { Glucose } \\
\text { content }\end{array}$ & & D & $\begin{array}{l}\beta \text {-Secretase } \\
\text { inhibition rate }\end{array}$ & & \\
\hline $\begin{array}{c}\text { Control } \\
\text { diet }\end{array}$ & 1.2 & $\mathrm{a}$ & 0.1 & 9.3 & $\mathrm{a}$ & 0.8 & 0 & $\mathrm{a}$ & 0 & 0.14 & $\mathrm{a}$ & 0 & 0 & $\mathrm{a}$ & 0 \\
\hline $\begin{array}{l}\text { HPT } \\
\text { KWB }\end{array}$ & 0.9 & $\mathrm{a}$ & 0 & 36.7 & b & 0.8 & 1.7 & b & 0 & 0.32 & b & 0.02 & 5 & $\mathrm{~b}$ & 0.7 \\
\hline $\begin{array}{l}\text { HPT } \\
\text { KBH }\end{array}$ & 2.9 & $\mathrm{~b}$ & 0 & 77.2 & c & 0.8 & 2.9 & c & 0 & 0.2 & $\mathrm{a}$ & 0.01 & 19 & $\mathrm{a}$ & 2.1 \\
\hline
\end{tabular}

Means with the same letter are not significantly different $(p<0.05)$.

Control meal:"Koshihikari” polished cooked rice.

HPT KBH rice: unpolished rice “Koshihikari”, black unpolished rice, “Okunomurasaki”, un-polishesuper-hard rice, "Chikushkona85' " and polished super-hard rice, "Goami2" blended in a ratio of 2:4:2:2 and cooked after a high-pressure-treatment (HPT).

HPT KWB rice: polished rice "Koshihikari", $\beta$-glucan-rich waxy hull-less barley, "Haneumamochi" blendedin a ratio of 5:5 and cooked after a high-pressure-treatment (HPT). 


\section{Glucose Content and BACE1 Inhibitory Activity}

Glucose concentrations of cooked rice samples were high in "Goami2" polished rice (0.284 g/L), "Haneumamochi" (0.230 g/L), and "Chikushi-kona 85" unpolished rice $(0.180 \mathrm{~g} / \mathrm{L})$, whereas glucose content in "Koshihikari" unpolished rice $(0.030 \mathrm{~g} / \mathrm{L})$ was very low (Table $4 \mathrm{~b}$ ). The glucose content remained almost identical between HPT (200 MPa 2 min) samples and untreated cooked rice (data not shown). However, glucose content was 2.3-fold higher $(\mathrm{P}<0.05)$ in cooked HPT KWB rice $(0.32 \mathrm{~g} / \mathrm{L})$ than in the cooked rice $(0.14 \mathrm{~g} / \mathrm{L})$ of the control diet (Table 7$)$. BACE1 is the first protease involved in the process of converting APP into $A \beta$ in the brain. BACE1 inhibitory activity for the HPT KBH rice $(19.0 \%)$, HPT KWB rice (5.0\%), and control diet $(0.0 \%)$, indicated that the BACE1 inhibitory activity of pigmented rice bran is much stronger than inhibitory activities in ordinary rice bran, as reported in our previous paper [38] (Table 7).

\section{Conclusion}

Because it has been reported that type- 2 diabetes increases the risk of $\mathrm{AD}$, we investigated whether $\mathrm{A} \beta$ generation could be prevented by consuming foods resistant to digestion. To identify natural, neuroactive and slowly digestive compounds with a potent inhibitory effect on BACE1, we evaluated black unpolished rice, ae-mutant unpolished rice, and polished waxy barley as dietary substitutes for polished, white rice typically consumed.

a) The texture of cooked HPT KBH and HPT KWB rice diets became more palatable following treatment with HTP. Test subjects who consumed these diets over the long term (12 weeks) had no medical emergencies; their safeties were not compromised, and they had no problem tolerating their assigned diets (determined from a questionnaire survey).

b) "Koshihikari" unpolished rice blended with black unpolished rice and super-hard rice (named HPT KBH rice, ratio 2:4:4), cooked after HPT, possessed high levels of resistant starch, and showed high inhibitory activities against BACE1, and had high antioxidant concentrations.

c) "Koshihikari" polished rice blended with polished waxy barley "Haneumamochi" (named HPT KWB, ratio 5:5), cooked after HPT, possessed high levels of dietary fiber and $\beta$-glucan

d) The BGL of test subjects 30 min after ingesting cooked HPT KBH (test meal-1) showed lower tendency after 12 weeks on the diets than that in subjects who consumed the control diet $(\mathrm{p}<0.1)$, and that of cooked HPT KWB (test meal-2) was significantly lower than that of control diet $(p<0.01)$.

e) After 12 weeks on their assigned diets, insulin levels in human test subjects at 120 min after ingesting cooked HPT $\mathrm{KBH}$ rice was significantly $(\mathrm{P}<0.05)$ lower than insulin levels in subjects ingesting the control diet.

f) After 12 weeks on their assigned diets, AUCi in human test subjects was significantly lower $(\mathrm{P}<0.05)$ at 90 and $120 \mathrm{~min}$ after ingesting the cooked HPT KWB diet than after ingesting the control diet.

g) The variation in $A \beta 42 / 40$ ratio after 6 weeks was significantly higher $(\mathrm{P}<0.04)$ for test subjects consuming the HPT KBH rice diet than that for subjects consuming the control diet.

The results of our long-term (12 week) human intervention study showed that ingesting $2.9 \mathrm{~g} / \mathrm{d}$ of $\beta$-glucan in the HPT KWB rice diet might have played a role in lowering postprandial glucose and insulin concentrations after meals. Furthermore, we propose that cooked KBH rice $(1.6 \mathrm{~g} / \mathrm{d}$ of RS and $0.2 \mathrm{~g} / \mathrm{d}$ of anthocyanin) could provide a nutritious, healthy, and palatable dietary alternative to traditional polished rice and that it would prevent abrupt increases in postprandial BGL, insulin levels, and inhibitory activity against $A \beta$ production, if consumed consistently as a regular, staple, component of one's diet. In addition, HPT KBH cooked rice might help prevent dementia due to the inhibitory effects we found in the $A \beta 42 / 40$ ratio in test subjects that consumed the diet for 12 weeks. We will continue this investigation on multiple-preventive rice products against diabetes and dementia by the combination of black rice and barley in the near future.

\section{Acknowledgement}

A part of this research was performed under the aid of Strategic Innovation Program of Japanese Cabinet Office.

\section{Reference}

1. (2016) World Health Organization Executive summary. Global report on diabetes p. 6-9.

2. (2016) NCD Risk Factor Collaboration (NCD-RisC) Worldwide trends in diabetes since 1980: a pooled analysis of 751 population-based studies with 4.4 million participants. Lancet 387(10027): 1513-1530.

3. Nantel G (2003) Glycemic carbohydrate, an international perspective. Nutr Rev 61: S34-S39.

4. Jenkins DJ, Wolever TM, Taylor RH, Barker H, Fielden H, et al. (1981) Glycemic index of foods: a physiological basis for carbohydrate exchange. Am J Clin Nutr 34(3): 362-366.

5. Venn BJ, Green TJ (2007) Glycemic index and glycemic load: measurement issues and their effect on diet-disease relationship. Eur J Clin Nutr 61(1): S122-S131.

6. Jenkins DJ, Kendall CW, Augustin LS, Franceschi S, Hamidi M, et al. (2002) Glycemic index: overview of implications in health and disease. Am J Clin Nutr 76(1): 266S-273S

7. Nishi A, Nakamura Y, Tanaka N, Satoh H (2001) Biochemical and genetic analysis of the effects of amylose-extender mutation in rice endosperm. Plant Physiol 127(2): 459-472.

8. Nakamura S, Satoh H, Ohtsubo K (2010) Palatable and bio-functional wheat/rice products developed from pre-germinated brown rice of super-hard cultivar EM10. Biosci Biotechnol Biochem 74(6): 1164-1172.

9. Wada T, Yamaguchi O, Miyazaki M, Miyahara K, Ishibashi M, et al. (2018) Development and characterization of a new rice cultivar, Chikushi-kona 85 derived from a starch-branching enzyme Ilb-deficient mutant line. Breeding Science 68(2): 278-283.

10. Yang CZ, Shu XL, Zhang LL, Wang XY, Zhao HJ, et al. (2006) Starch properties of mutant rice high in resistant starch. J Agric Food Chem 54(2): 523-528. 
11. Goddard M, Yong G, Marcus R (1984) The effect of amylose content on insulin and glucose responses to ingested rice. Am J Clin Nutr 39(3): 388-392.

12. Kang HJ, Wang IKH, Kim KS, Choi HC (2003) Comparative structure and physicochemical properties of Ilpumbyeo, a high-quality Japonica rice, and its mutant, Suwon 464. J Agric Food Chem 51: 6598-6603.

13. Theuwissen E, Mensink RP (2007) Simultaneous intake of betaglucan and plant stanol esters affects lipid metabolism in slightly hypercholesterolemic subjects. J Nutr 137(3): 583-588.

14. Yokoyama W, Hudson CA, Knuckles BE, Chiu MM, Sayre RN, et al. (1997) Effect of barley $\beta$-glucan in durum wheat pasta on human glycemic response. Cereal Chem 74(3): 293-296.

15. Ullrich SE, Clancy JA, Eslick RF, Lance RCM (1986) Beta-glucan content viscosity of extracts from waxy barley. Journal of Cereal Science 4(3): 279-285.

16. Kim HJ, White PJ (2009) In vitro fermentation of oat flours from typical and high betaglucan oat lines. J Agric Food Chem 57(16): 7529-7536.

17. Amaral L, Morgan D, Stephen AM (1992) Effect of propionate on lipidmetabolism in healthy-human subjects. FASEB J 6(5): A1655.

18. Ide T, Okamatsu H, Sugano M (1978) Regulation by dietary fats of 3-hydroxy-3methylglutaryl-coenzyme-a reductase in rat-liver. J Nutr 108(4): 601-612.

19. Behall KM, Scholfield DJ, Hallfrisch JG, Liljeberg Elmstahl HG (2006) Consumption of both resistant starch and beta-glucan improves postprandial plasma glucose and insulin in women. Diabetes Care 29(5): 976-981.

20. Behall KM, Scholfield DJ, Yuhaniak I, Canary J (1989) Diets containing high amylose vs amylopectin starch- Effects on metabolic variables in human-subjects. Am J Clin Nutr 49(2): 337-344.

21. Robertson MD, Bickerton AS, Dennis AL, Vidal H, Fravn KN, et al. (2005) Insulin sensitizing effects of dietary resistant starch and effects on skeletal muscle and adipose tissue metabolism. Am J Clin Nutr 82(3): 559-567.

22. Hayashi R, Hayashida A (1989) Increased amylose digestibility of pressure-treated starch. Agric Biol Chem 53: 2543-2544.

23. Hayashi R (1989) Application of high pressure to food processing and preservation: philosophy and development. Eng Food 2: 815-826

24. Yamakura M, Haraguchi K, Okadome H, Suzuki K, Thi Tran U, et al. (2005) Effect of soaking and high-pressure treatment on the qualities of cooked rice. J Appl Glycosci 52: 85-93.

25. Nakamura S, Ohtsubo K (2015) Improvement of palatability and inhibition of abrupt increase in postprandial blood glucose level by the boiled rice after soaking with functional food ingredients. J Appl Glycosci 62: 53-63.

26. Nakamura S, Hara T, Yamazaki A, Kobayashi A, Maeda S, et al. (2018) Trial for the development of biofunctional foods to prevent diabetes and dementia using a high-pressure treatment. J Diabetes Obes 5(1): 22-30.

27. Ohara T, Doi Y, Ninomiya T, Hirakawa Y, Hata J, et al. (2011) Glucose tolerance status and risk of dementia in the community. The Hisayama Study Neurology 77(12): 1126-1134.

28. Biessels G J, Staekenborg S, Brunner E, Brayne C (2006) Risk of dementia in diabetes mellitus: a systematic review. Brain Stimulation 5(1): 64-74.

29. Kasuga K, Kaneko H, Nishizawa M, Onodera O, Ikeuchi T, et al. (2007) Generation of intracellular domain of insulin receptor tyrosine kinase by gamma-secretase. Biochem Biophys Res Commun 17: 360(1): 90-96.

30. Mandal PK, Kansara K, Dabas A (2017) The GABA-working memory relationship in Alzheimer's disease. J Alzheimers Dis Rep 1: 43-45.

31. Kawamura K, Umemura T, Hotta N (2012) Cognitive impairment in diabetic patients: Can diabetic control prevent cognitive decline? J Diabetes Investig 3(5): 413-423.
32. Tokutake T, Kasuga K, Yajima R, Sekine Y, Tezuka T. et al. (2012) Hyperphosphorylation of tau induced by naturally secreted amyloid- $\beta$ at nanomolar concentrations is modulated by insulin-dependent AktGSK3 $\beta$ signaling pathway. J Biol Chem 287(12): 35222-35233

33. Taniguchi H, Hashimoto H, Hosoda A, Kometani T (2012) Functionality of compounds contained in rice bran and their improvement. Nippon Shokuhin Kagaku Kogaku Kaishi 59(7): 301-318.

34. Jonsen MK, Koh-Banerjee P, Hu FB, Franz M, Sampsou L, et al. (2004) Intakes of whole grains bran and germ and the risk of coronary heart disease in men. Am J Clin Nutr 80(6): 1492-1499.

35. Qureshi A A, Sami SA, Khan FA (2002) Effects of stabilized rice bran its soluble and fiber fractions on blood glucose levels and serum lipid parameters in humans with diabetes mellitus types I and II. J Nutr. Biochem 13(3): 175-187.

36. Abe T, Taniguchi M (2014) Identification of myo-inositol hexakisphosphate (IP6) as a $\beta$ - secretase 1(BACE1) inhibitory molecule in rice grain extract and digest. FEBS Open Bio 4: 162-167.

37. Sutharut J, Sudarat J (2012) Total anthocyanin content and antioxidant activity of germinated colored rice. Int Food Res J 19(1): 215-221.

38. Nakamura S, Hara T, Joh T, Kobayashi A, Yamazaki A, et al. (2017) Effects of super-hard rice bread blended with black rice bran on amyloid $\beta$ peptide production and abrupt increase in postprandial blood glucose levels in mice. Biosci Biotechnol Biochem 81(2): 323-334.

39. Juliano B O, Onate LU, Mundo AM (1965) A simplified assay for milled rice amylose. Food Technol 19: 1006-1011.

40. Nakamura S, Satoh H, Ohtsubo K (2015) Development of formulae for estimating amylose content, amylopectin chain length distribution, and resistant starch content based on the iodine absorption curve of rice starch. Biosci Biotechnol Biochem 79(3): 443-455.

41. Okadome H, Toyoshima H, Ohtsubo K (1999) Multiple measurements of physical properties of individual cooked rice grains with a single apparatus. Cereal Chem 76: 855-860.

42. Prior RL, Hoang H, Gu L, Wu X, Bacchiocca M, et al. (2003) Assay for hydrophilic and lipophilic antioxidant capacity (oxygen radical absorbance capacity (ORACFL) of plasma and other biological and food samples. J Agric Food Chem 51(11): 3273-3279.

43. Ito M, Ohara E, Kobayashi A, Yamazaki A, Kaji R, et al. (2011) Antioxidant capacities and polyphenol content of colored rice cultivars. Nippon Shokuhin Kagaku Kogaku Kaishi 58(12): 576-582.

44. Watanabe J, Oki T, Takebayashi J, Yamasaki K, Takano-Ishikawa Y, et al. (2012) Method validation by interlaboratory studies of improved hydrophilic oxygen radical absorbance capacity methods for the determination of antioxidant capacities of antioxidant solutions and food extracts. Anal Sci 28(2): 159-165.

45. Watanabe J, Oki T, Takebayashi J, Yamasaki K, Takano-Ishikawa Y, et al. (2013) Improvement of the lipophilic-oxygen radical absorbance capacity (L-ORAC) method and single-laboratory validation. Biosci. Biotechnol. Biochem 77(4): 857-859.

46. Aoe S, Ichinose Y, Kahyama N, Takahashi A, Abe D, et al. (2017) Effects of $\beta$-glucan barley on visceral fat obesity in Japanese individuals: A randomized double-blind study. J Nutr 42: 1-6.

47. Aoe $S$ (2015) Physiological function of $\beta$-glucan in barley. Journal for the integrated study of dietary habits $1: 3-6$.

48. Murao S, Oka T, Nagamachi N, Honda K, Arakawa Y, et al. (2010) LDL cholesterol to HDL cholesterol ratio and its relationship with other cardiovascular risk factors in Japanese population. Ningen Dock 25(1): 65-70.

49. Ullrich SE, Clancy JA, Eslick RF, Lance RCM (1986) $\beta$-glucan content and viscosity of extracts from Barly. Journal of Cereal Science 4(3): 279-285.

50. Gallant D J, Bouchet B, Baldwin PM (1997) Microscopy of starch evidence of a new level of granule organization. Carbohydrate Polym 32(3-4): 177-191. 
51. Nakamura Y, Sakurai A, Inaba Y, Kimura K (2002) The fine structure of amylopectin in endosperm from Asian cultivated rice can be largely classified into two classes. Starch/Starke 54: 117-131.

52. Hizukuri S (1986) Polymodal distribution of the chain lengths of amylopectins and its significance. Carbohydr. Res 147(2): 342-347.

53. Robin JP, Mercier C, Charbonniere R, Guibot A (1974) Gel filtration and enzymatic studies of insoluble residues from prolonged acid treatment of potato starch. Cereal Chem 51: 389-406.

54. Panlasigui L, Thompson LU (2006) Blood glucose lowering effects of brown rice in normal and diabetic subjects. J Food Sci Nutr 57(3-4): 151-158.

55. Barter P, Gotto AM, LaRosa JC, Maroni J, Szarek M, et al. (2007) HDL cholesterol, very low levels of LDL cholesterol, and cardiovascular events. N Engl J Med 27: 357(13): 1301-1310.

56. Reader DM, O’Connell BS, Johnson ML (2002) Glycemic and insulinemic response of subjects with type2 diabetes after consumption of three energy bars. J Am Diet Assoc 102(8): 1139-1142.

57. Fernandez ML, Webb D (2008) The LDL to HDL cholesterol ratio as a valuable tool to evaluate coronary heat disease risk. J Am Coll Nutr 27(1): 1-5.

58. Manninen V, Tenkanen L, Koskinen P, Huttunen JK, Manttari M, et al. (1992) Joint effects of serum triglyceride and LDL cholesterol and HDL

ISSN: 2574-1241

DOI: 10.26717/BJSTR.2019.20.003483

Ken'ichi Ohtsubo. Biomed J Sci \& Tech Res

(C) This work is licensed under Creative Commons Attribution 4.0 License

Submission Link: https://biomedres.us/submit-manuscript.php cholesterol concentrations on coronary heart disease risk in the Helsinki Heart Study. Implications for treatment. Circulation 85(1): 37-45.

59. Graff-Radford NR, Crook JE, Lucas J, Boeve BF, Knopman DS, et al. (2007) Association of low plasma Abeta42/Abeta40 ratios with increased imminent risk for mild cognitive impairment and Alzheimer disease. Arch. Neurol 64(3): 354-362.

60. Van Oijen, Hofman A, Soares HD, Korudstaal PJ, Breteler MM, et al. (2006) Plasma Abeta (1-40) and Abeta (1-42) and the risk of dementia: a prospective case-cohort study. Lancet Neurol 5(8): 655-660.

61. Nakamura A, Kaneko N, Villemagne VL, Kato T, Doecke J, et al. (2018) High-performance plasma amyloid- $\beta$ biomarkers for Alzheimer's disease. Nature 554(7691): 249-254.

62. Ling WH, Cheng QX, Ma J, Wang T (2001) Red and black rice decrease atherosclerotic plaque formation and increase antioxidant status in rabbits. J Nutr 131(5): 1421-1426.

63. Tsuda T, Horio F, Uchida K, Aoki H, Osawa T, et al. (2003) Dietary cyaniding 3-0-beta-D-glucoside purple corn color prevents obesity and ameliorates hyperglycemia in mice. J Nutr 133(7): 2125-2130.

64. Suzuki M, Kataoka T, Ohtsubo K (2014) Variation in the mineral content of 8 cultivars of pigmented brown rice. Nippon Shokuhin Kagaku Kogaku Kaishi 61(9): 427-432.

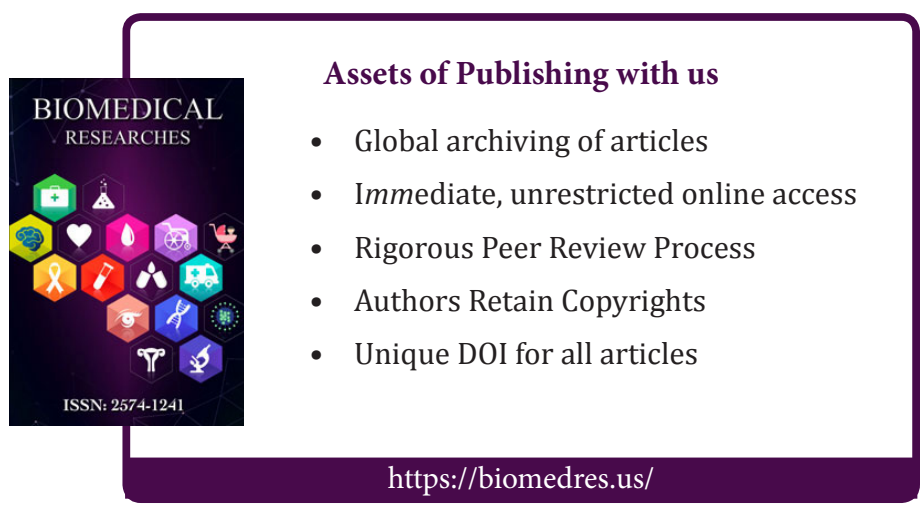

